\title{
Papers
}

\section{Sickness absence as a global measure of health: evidence from mortality in the Whitehall II prospective cohort study}

\author{
Mika Kivimäki, Jenny Head, Jane E Ferrie, Martin J Shipley, Jussi Vahtera, Michael G Marmot
}

\begin{abstract}
Objective To examine the association between sickness absence and mortality compared with associations between established health indicators and mortality.

Design Prospective cohort study. Medical

examination and questionnaire survey conducted in 1985-8; sickness absence records covered the period 1985-98.

Setting 20 civil service departments in London. Participants 6895 male and 3413 female civil servants aged $35-55$ years.

Main outcome measure All cause mortality until the end of 1999.

Results After adjustment for age and grade, men and women who had more than five medically certified absences (spells $>7$ days) per 10 years had a mortality 4.8 (95\% confidence interval 3.3 to 6.9$)$ and 2.7 (1.5 to 4.9) times greater than those with no such absence. Poor self rated health, presence of longstanding illness, and a measure of common clinical conditions comprising diabetes, diagnosed heart disease, abnormalities on electrocardiogram, hypertension, and respiratory illness were all associated with mortality-relative rates between 1.3 and 1.9. In a multivariate model including all the above health indicators and additional health risk factors, medically certified sickness absence remained a significant predictor of mortality. No linear association existed between self certified absence (spells 1-7 days) and mortality, but the findings suggest that a small amount of self certified absence is protective.

Conclusion Evidence linking sickness absence to mortality indicates that routinely collected sickness absence data could be used as a global measure of health differentials between employees. However, such approaches should focus on medically certified (or long term) absences rather than self certified absences.
\end{abstract}

\section{Introduction}

Controversy exists about the status of sickness absence as a global measure of health. According to one view, recorded sickness absences accurately reflect the health of working populations, at least when health is understood in terms of physical and social function- ing. ${ }^{1}$ An advantage is that data on absence are often collected routinely by workplaces, which minimises potential recall and response set biases attributable to self reported indicators of health. ${ }^{2}$ Longer periods of sickness absence are based on a physician's examination rather than self evaluation, further justifying their adequacy as a health indicator.

The other view of sickness absence as an indicator emphasises the variable relation between illness and absence. Employees may take sick leave without actual illness or have illness without taking sick leave. Factors that may increase absence rates include generous sick pay schemes, use of absence as a coping strategy to reduce stress and prevent ill health, and need for support among family members. ${ }^{3-5}$ Job insecurity may decrease the likelihood of taking sick leave. ${ }^{67}$ In addition to these factors, different criteria for disability between occupations may attenuate the association between health and sickness absence. ${ }^{2}$

One way to increase understanding of the status of sickness absence as a measure of health is to analyse mortality data. Unpublished data from Finnish municipal employees indicate an association between medically certified sick leaves and mortality. ${ }^{8}$ These findings may not be generalisable to other countries with different jurisdictions. A major limitation in available evidence is a lack of studies examining the predictive validity of sickness absence for mortality compared with the predictive validity of more established measures of health.

The Whitehall II study of British civil servants has shown a strong association between indicators of ill health and sickness absence, particularly for longer spells of absence. ${ }^{1}$ Factors that have predicted health, such as low socioeconomic status, heavy alcohol intake, widowhood and being single, and poor job control, have also been associated with increased absence rates in this cohort. ${ }^{19-13}$ This report from the Whitehall II study examines associations of sickness absence with all cause mortality. To determine its value as a health indicator, we compared the predictive validity of sickness absence with that of more established indicators of health.

\section{Methods}

\section{Participants}

The target population for the Whitehall II study was all London based office staff, aged 35-55, working in 20
Finnish Institute of Occupational Health,

Topeliuksenkatu 41 aA, FIN-00250

Helsinki, Finland

Mika Kivimäki

professor

Jussi Vahtera

senior researcher

International

Centre for Health and Society,

Department of

Epidemiology and

Public Health,

University College

London Medical

School, London

WC1E 6BT

Jenny Head

senior lecturer

Jane E Ferrie

senior research fellow

Martin J Shipley

senior lecturer

Michael G Marmot

professor

Correspondence to: M Kivimäki

mika.kivimaki@ttl.fi

bmj.com 2003:327:364 
civil service departments. With a response rate of $73 \%$, the final cohort consisted of 10308 people: 6895 men and 3413 women. ${ }^{14}$ The true response rate was higher, however, because around $4 \%$ of people invited were not eligible for inclusion. Although most respondents were white collar staff, they covered a wide range of grades (and salaries) from office support staff to permanent secretary.

\section{Measurements}

Baseline screening, carried out between 1985 and 1988, included the following measurements of health status: self rated health over the previous 12 months; presence of longstanding illness, disability, or infirmity; minor psychiatric morbidity (score $>4 v 0-4$ on the 30 item general health questionnaire); presence of 17 different symptoms in the previous 14 days; presence of recurring health problems in the previous year; and a composite physical illness indicator (diabetes, diagnosed heart disease, abnormalities on electrocardiogram, hypertension, respiratory illness). In addition, the following specific medical and health related conditions were determined: angina as assessed by the Rose angina questionnaire; diagnosis of heart disease by a doctor; probable or possible ischaemia on electrocardiogram; hypertension (antihypertensive drugs or blood pressure $>160 / 95 \mathrm{~mm} \mathrm{Hg}$ ); high serum cholesterol concentration $(>6.2 \mathrm{mmol} / \mathrm{l})$; obesity from recordings of weight and height (BMI $>30 \mathrm{~kg} / \mathrm{m}^{2}$ ); and smoking status. Some baseline data were missing for the measures of longstanding illness, symptoms, and recurring health problems, as these were introduced after the start of the baseline survey. Where data were missing for these three measures, we used values from the follow up survey (1989-90). Few data were missing for the other baseline measures. Further details of all these measures have been reported previously. ${ }^{14} 15$

We obtained computerised sickness absence records from 1 January 1985 to 31 December 1998 from civil service pay centres..$^{10}$ These records included the first and last dates of all absences. For absences of seven calendar days or less, civil servants were able to complete their own certificate and explain the absence. For absences longer than seven days, a medical certificate was required. We checked sickness absence records for inconsistencies. We merged overlapping, consecutive, or duplicate spells of sickness absence after taking account of weekends and public holidays. For each employee, we calculated the number of medically certified ( $>7$ days) and self certified (1-7 days) spells of sickness absence a year. We categorised both indices of sickness absence into four groups according to the rate of sickness absence.

We obtained mortality data for all the participants who died between date of entry into the study (1985-8) and 31 December 1999 from the national mortality register kept by the National Health Services Central Registry, by using the NHS identification number assigned to each British citizen.

\section{Statistical analysis}

We used Poisson regression analysis to study sex differences in sickness absence adjusted for age and grade. ${ }^{10}$ For sex differences in other health indicators, we used appropriate logistic or linear regression analysis. We calculated Cox proportional hazard models separately for men and women to study the associations of sickness absence, health indicators, and specific health risks with mortality. In the first step we adjusted hazard ratios and their $95 \%$ confidence intervals for age and grade. The second step tested a multivariate model of those indicators of sickness absence and all the health measures that separately predicted mortality. In a third step we excluded any possible confounding arising from the assessment of sickness absence in parallel with follow up for mortality. We thus replicated the first and second steps in a subcohort of employees who remained in civil service employment until the end of 1989. We determined their absence level from sickness records up to 1990, whereas the follow up for mortality was from 1990 onwards. Finally, to confirm that the association between absence and mortality was not confounded by an excess rate of sickness absence shortly before dying, we excluded those employees who died before 1992 (that is, deaths in the two years immediately after the assessment of sickness absence) from the subcohort analysis. We used the SAS 8.2 program for all analyses.

\section{Results}

Of the 10308 participants, mortality data were available for 10293 employees. During the mean follow up period of 12.7 (SD 1.5) years, 355 participants died. We obtained follow up data on sickness absence for 9179 employees (302 deaths). We identified 11539 medically certified absence spells and 89491 self certified sickness absence spells between 1985 and 1998.

Table 1 presents distributions of the study variables by sex. Men were younger and more often employed in higher grade jobs than were women. After adjustment for these differences, women had a 1.5 -fold $(95 \%$ confidence interval 1.4 to 1.9 ) higher risk of medically certified sickness absence and a 1.2-fold (1.1 to 1.2) higher risk of self certified sickness absence compared with men. Corresponding ratios for poor self rated health and minor psychiatric morbidity were 1.5 (1.3 to 1.6 ) and 1.5 (1.4 to 1.7). Women more often reported symptoms and health problems $(\mathrm{P}<0.01)$, but we found no sex differences in the prevalence of longstanding illness, disability, or infirmity or the composite physical illness indicator. Men had a 1.7 (1.3 to 2.2) times greater adjusted mortality than women.

Table 2 shows the associations of sickness absence and health indicators with mortality for men and women. These associations are adjusted for age and grade but not for the other variables in the table. Mortality increased as the medically certified absence rates increased ( $\mathrm{P}$ for linear trend $<0.001$ in both sexes). Men and women with more than five such absence spells per 10 years had mortality 4.8 and 2.7 times higher than those with no such absences. A U shaped association existed between self certified absence and mortality; this was significant for men $(\mathrm{P}=0.03)$ but not for women $(\mathrm{P}=0.90)$. Average or worse self rated health, presence of longstanding illness, and presence of physical illness (in men) were associated with higher mortality-ratios between 1.3 and 1.9. Diagnosed heart disease, hypertension, smoking, ischaemia (in men), and cholesterol concentration $>6.2 \mathrm{mmol} / \mathrm{l}$ (in men) also separately predicted mortality (data not shown). 
Table 3 shows results of multivariate analyses including all the health indicators that separately predicted mortality. Only medically certified sickness absence and the physical illness indicator (in men) remained as statistically significant predictors. The significant effect of sickness absence also remained unchanged after an additional adjustment for diagnosed heart disease, probable or possible ischaemia, hypertension, smoking, and high cholesterol (mortality ratios for high absence 4.4 (2.9 to 6.7) in men and 3.3 (1.6 to 6.8) in women). Adjustment for the health indicators in table 3 had little effect on the $U$ shaped association between self certified absence and mortality ( $\mathrm{P}$ value for curve linear trend 0.02 for men and 0.88 for women).

Table 4 presents associations between medically certified sickness absence and mortality in a subcohort of employees with absence records up to the end of 1989 and follow up for mortality from 1990 onwards. We collapsed the categories of $>0$ to 2 and $>2$ to 5 absence spells per 10 years to achieve a sufficient number of cases in all categories. Men and women with more than five absence spells per 10 years had mortality 2.1 and 2.7 times higher than those with no absences. In all univariate and multivariate models, the association of sickness absence with mortality was stronger than those observed for other health indicators. The significant effect of sickness absence remained after adjustment for other health indicators and also after an additional adjustment for diagnosed heart disease, probable or possible ischaemia, hypertension, smoking, and high cholesterol (mortality ratios for high absence 1.7 (1.0 to 2.9) in men and 2.2 (1.29 to 4.0$)$ in women).

In the subcohort analysis, exclusion of the 21 employees who died in the two years immediately after the assessment of sickness absence had little effect on the results. After adjustment for age and grade, mortality ratios in men and women with more than five absence spells per 10 years were 2.1 (1.2 to 3.4) and 2.3 (1.3 to 4.2). Corresponding figures in multivariate analyses including all the health indicators that separately predicted mortality were 1.8 (1.1 to 3.1 ) and 2.2 (1.2 to 4.1). Thus absence close to death is an unlikely source of confounding in the observed association between medically certified sickness absence and mortality.

\section{Discussion}

This study shows that medically certified sickness absences, data collected as a byproduct of the clinical care of working populations, predict mortality as well as or better than established indicators of health such as poor self rated health, minor psychiatric morbidity, and presence of longstanding physical illness, disability, or infirmity. To our best knowledge, this is the first mortality study to compare the predictive validity of sickness absence with that of other measures of health.

We found that male and female employees taking a medically certified sick leave ( $>7$ days) on average more than once in two years had a mortality two to five times greater than their colleagues with no such absence. These figures are in line with findings for Finnish municipal employees, for whom medical examination is needed after three instead of seven sick days. ${ }^{8}$ In the Finnish study, the overall mortality risk
Table 1 Characteristics of participants* in the Whitehall II study. Values are numbers (percentages)

\begin{tabular}{|c|c|c|}
\hline Characteristic & Men & Women \\
\hline \multicolumn{3}{|l|}{ Age at baseline (years): } \\
\hline $35-39$ & $2013(29)$ & $796(23)$ \\
\hline $40-44$ & $1871(27)$ & $788(23)$ \\
\hline $45-49$ & $1338(19)$ & $764(22)$ \\
\hline $50-55$ & $1666(24)$ & $1057(31)$ \\
\hline \multicolumn{3}{|l|}{ Grade at baseline: } \\
\hline Administrative & $2644(38)$ & $379(11)$ \\
\hline Professional or executive & $3605(52)$ & $1336(39)$ \\
\hline Clerical or support & $639(9)$ & $1696(50)$ \\
\hline \multicolumn{3}{|c|}{ Medically certified absence (spells per 10 years): } \\
\hline 0 & $3796(60)$ & $1039(36)$ \\
\hline$>0$ to 2 & $1207(19)$ & $513(18)$ \\
\hline$>2$ to 5 & $838(13)$ & $644(22)$ \\
\hline$>5$ & $445(7)$ & $688(24)$ \\
\hline \multicolumn{3}{|c|}{ Self certified absence (spells per 10 years): } \\
\hline 0 & $1137(18)$ & $297(10)$ \\
\hline$>0$ to 10 & $2718(43)$ & $761(26)$ \\
\hline$>10$ to 20 & $1262(20)$ & $735(25)$ \\
\hline$>20$ & $1169(19)$ & $1091(38)$ \\
\hline \multicolumn{3}{|l|}{ Self rated health status: } \\
\hline Very good or good & $5323(78)$ & $2160(64)$ \\
\hline Average or worse & $1539(22)$ & $1235(36)$ \\
\hline \multicolumn{3}{|c|}{ Longstanding illness, disability, or infirmity: } \\
\hline No & $4426(75)$ & $2105(67)$ \\
\hline Yes & $2115(32)$ & $1059(33)$ \\
\hline \multicolumn{3}{|c|}{ No of recurrent health problems: } \\
\hline 0 & $2090(32)$ & $769(24)$ \\
\hline $1-3$ & $3951(61)$ & $1962(62)$ \\
\hline$>3$ & $484(7)$ & $418(13)$ \\
\hline \multicolumn{3}{|l|}{ No of symptoms: } \\
\hline 0 & $1395(21)$ & $452(14)$ \\
\hline $1-4$ & $3991(61)$ & $1876(60)$ \\
\hline$>4$ & $1149(18)$ & $816(26)$ \\
\hline \multicolumn{3}{|c|}{ Minor psychiatric morbidity (general health questionnaire score $>4$ ): } \\
\hline No & $5134(75)$ & $2343(70)$ \\
\hline Yes & $1733(25)$ & $1029(30)$ \\
\hline \multicolumn{3}{|l|}{ Physical illness indicatort: } \\
\hline No & $5979(89)$ & $2894(88)$ \\
\hline Yes & 766 (11) & $393(12)$ \\
\hline \multicolumn{3}{|l|}{ All cause mortality: } \\
\hline Alive & $6645(96)$ & $3293(97)$ \\
\hline Dead & $243(4)$ & $112(3)$ \\
\hline
\end{tabular}

*For whom mortality data were available.

†Diabetes, diagnosed heart disease, hypertension, abnormalities on electrocardiogram, respiratory illness.

was greater in employees with more than one medically certified absence a year than in those with no absence. Our results are also in line with the classic study of British post office staff in 1972-5, which showed an association between duration of medically certified absences and medical wastage (a term used to describe the sum of deaths in service under age 60 and medical retirements). ${ }^{16}$

Poor self rated health status was associated with a 1.6-fold to 1.8-fold excess of mortality. This accords with the risk ratios of 1.5 and 1.6 reported for poor self rated health in previous studies of middle aged populations. ${ }^{17-19}$ The associations of both self rated health and longstanding illness with mortality were substantially attenuated and became statistically nonsignificant in multivariate models including medically certified sickness absence. In contrast, the association between sickness absence and mortality remained almost unaffected by inclusion of other measures of ill health. If mortality is taken as the criterion for validity, 
Table 2 Hazard ratios for all cause mortality by levels of sickness absence and health indicators among civil servants in the Whitehall II study. Adjusted for age and grade

\begin{tabular}{|c|c|c|c|c|}
\hline & \multicolumn{2}{|c|}{ Men } & \multicolumn{2}{|c|}{ Women } \\
\hline & No of deaths & Hazard ratio $(95 \% \mathrm{Cl})$ & No of deaths & Hazard ratio $(95 \% \mathrm{Cl})$ \\
\hline \multicolumn{5}{|c|}{ Medically certified absence ${ }^{*}$ (spells per 10 years): } \\
\hline 0 & 82 & 1.00 & 17 & 1.00 \\
\hline$>0$ to 2 & 31 & $1.30(0.86$ to 1.98$)$ & 11 & 1.26 (0.59 to 2.71$)$ \\
\hline$>2$ to 5 & 47 & 2.24 (1.55 to 3.23$)$ & 20 & $1.60(0.83$ to 3.08$)$ \\
\hline$>5$ & 55 & 4.77 (3.31 to 6.88$)$ & 39 & 2.72 (1.51 to 4.91$)$ \\
\hline \multicolumn{5}{|c|}{ Self certified absence $†$ (spells per 10 years): } \\
\hline 0 & 39 & 1.00 & 9 & 1.00 \\
\hline$>0$ to 10 & 70 & 0.76 (0.51 to 1.13$)$ & 17 & $0.62(0.28$ to 1.40$)$ \\
\hline$>10$ to 20 & 41 & 0.90 (0.57 to 1.41$)$ & 24 & $0.78(0.36$ to 1.71$)$ \\
\hline$>20$ & 65 & $1.40(0.91$ to 2.16$)$ & 37 & 0.80 (0.38 to 1.68$)$ \\
\hline \multicolumn{5}{|l|}{ Self rated health status: } \\
\hline Very good or good & 161 & 1.00 & 52 & 1.00 \\
\hline Average or worse & 80 & 1.58 (1.20 to 2.07$)$ & 58 & $1.78(1.22$ to 2.60$)$ \\
\hline \multicolumn{5}{|c|}{ Longstanding illness, disability, or infirmity: } \\
\hline No & 126 & 1.00 & 50 & 1.00 \\
\hline Yes & 92 & $1.31(1.00$ to 1.72$)$ & 47 & $1.74(1.16$ to 2.59$)$ \\
\hline \multicolumn{5}{|c|}{ No of recurrent health problems: } \\
\hline 0 & 44 & 1.00 & 24 & 1.00 \\
\hline $1-3$ & 94 & $1.08(0.81$ to 1.44$)$ & 45 & 0.78 (0.51 to 1.19$)$ \\
\hline$>3$ & 21 & 1.50 (0.96 to 2.34$)$ & 10 & $0.73(0.38$ to 1.39$)$ \\
\hline \multicolumn{5}{|l|}{ No of symptoms: } \\
\hline 0 & 34 & 1.00 & 15 & 1.00 \\
\hline $1-4$ & 90 & $1.06(0.78$ to 1.50$)$ & 45 & 0.74 (0.44 to 1.26$)$ \\
\hline$>4$ & 34 & $1.26(0.83$ to 1.92$)$ & 19 & $0.65(0.35$ to 1.21$)$ \\
\hline \multicolumn{5}{|c|}{ Minor psychiatric morbidity (general health questionaire score $>4$ ): } \\
\hline No & 186 & 1.00 & 76 & 1.00 \\
\hline Yes & 56 & $0.94(0.70$ to 1.27$)$ & 34 & $1.14(0.76$ to 1.71$)$ \\
\hline \multicolumn{5}{|c|}{ Physical illness indicatorł: } \\
\hline No & 190 & 1.00 & 93 & 1.00 \\
\hline Yes & 49 & 1.88 (1.37 to 2.58$)$ & 15 & $1.11(0.64$ to 1.92$)$ \\
\hline
\end{tabular}

${ }^{*} \mathrm{P}$ for linear trend $<0.001$ in men and women.

tP for curvilinear trend 0.03 for men and 0.90 for women.

‡Diabetes, diagnosed heart disease, hypertension, abnormalities on electrocardiogram, respiratory illness.

Table 3 Hazard ratios for all cause mortality by levels of sickness absence and health indicators among civil servants in a multivariate model. Adjusted for age, grade, and predictors shown in table

\begin{tabular}{|c|c|c|c|c|}
\hline & \multicolumn{2}{|c|}{ Men $(n=5894)$} & \multicolumn{2}{|c|}{ Women $(n=2610)$} \\
\hline & No of deaths & Hazard ratio $(95 \% \mathrm{Cl})$ & No of deaths & Hazard ratio $(95 \% \mathrm{Cl})$ \\
\hline \multicolumn{5}{|c|}{ Medically certified sickness absence ${ }^{\star}$ (spells per 10 years): } \\
\hline 0 & 75 & 1.00 & 12 & 1.00 \\
\hline$>0$ to 2 & 29 & 1.29 (0.84 to 1.99$)$ & 11 & 1.78 (0.78 to 4.05$)$ \\
\hline$>2$ to 5 & 39 & 1.96 (1.32 to 2.92$)$ & 18 & $1.96(0.93$ to 4.12$)$ \\
\hline$>5$ & 51 & 4.74 (3.18 to 7.07$)$ & 34 & 3.14 (1.56 to 6.29$)$ \\
\hline \multicolumn{5}{|l|}{ Self rated health status: } \\
\hline Very good or good & 133 & 1.00 & 39 & 1.00 \\
\hline Average or worse & 61 & $1.17(0.85$ to 1.63$)$ & 36 & $1.14(0.69$ to 1.85$)$ \\
\hline \multicolumn{5}{|c|}{ Longstanding illness, disability, or infirmity: } \\
\hline No & 112 & 1.00 & 38 & 1.00 \\
\hline Yes & 82 & $0.95(0.70$ to 1.29$)$ & 37 & $1.45(0.89$ to 2.34$)$ \\
\hline \multicolumn{5}{|c|}{ Physical illness indicatort: } \\
\hline No & 157 & 1.00 & 62 & 1.00 \\
\hline Yes & 37 & 1.46 (1.01 to 2.11$)$ & 13 & $1.18(0.64$ to 2.20$)$ \\
\hline
\end{tabular}

${ }^{*} P$ for linear trend $\leq 0.001$ in men and women.

†Diabetes, diagnosed heart disease, hypertension, abnormalities on electrocardiogram, respiratory illness

this evidence supports the interpretation that medically certified sickness absence is a better measure of global health than these widely used self reported indicators.

Adjustment for information from clinical examination, medical records, laboratory analyses of blood samples, and electrocardiographic monitoring indicated that the association between sickness absence and mortality may not be exclusively attributable to objective measures of physical illness and specific medical conditions. Sickness absence may capture indicators of morbidity that are not fully reflected by an additive measurement of disease with available measures. Absence may reflect distal risk factors for mortality. For example, a hostile personality and work stress are predictors of premature death in initially healthy populations, ${ }^{202}$ and sickness absence is associated with these factors. ${ }^{22}$ 
Table 4 Hazard ratios for all cause mortality after 1989 by levels of sickness absence between 1985 and 1989 among civil servants who remained in civil service employment until the end of 1989

\begin{tabular}{|c|c|c|c|}
\hline & \multirow[b]{2}{*}{ No (deaths)* } & \multicolumn{2}{|c|}{ Hazard ratio $(95 \% \mathrm{CI})$} \\
\hline & & Univariate model† & Multivariate model‡ \\
\hline \multicolumn{4}{|l|}{ Men $(n=5011)$} \\
\hline \multicolumn{4}{|c|}{ Medically certified absence§ (spells per 10 years): } \\
\hline 0 & $3974(88)$ & 1.00 & 1.00 \\
\hline$>0$ to 5 & $676(29)$ & $1.73(1.13$ to 2.64$)$ & $1.63(1.06$ to 2.51$)$ \\
\hline$>5$ & $361(22)$ & 2.07 (1.27 to 3.38$)$ & 1.89 (1.14 to 3.12$)$ \\
\hline \multicolumn{4}{|l|}{ Self rated health status: } \\
\hline Very good or good & $3951(99)$ & 1.00 & 1.00 \\
\hline Average or worse & $1060(40)$ & 1.38 (0.95 to 2.01$)$ & $1.17(0.79$ to 1.73$)$ \\
\hline \multicolumn{4}{|c|}{ Longstanding illness, disability, or infirmity: } \\
\hline No & $3394(80)$ & 1.00 & 1.00 \\
\hline Yes & $1617(59)$ & $1.32(0.94$ to 1.85$)$ & 1.11 (0.78 to 1.59$)$ \\
\hline \multicolumn{4}{|c|}{ Physical illness indicatorף: } \\
\hline No & $4445(112)$ & 1.00 & 1.00 \\
\hline Yes & $566(27)$ & 1.78 (1.16 to 2.71$)$ & 1.59 (1.03 to 2.45$)$ \\
\hline \multicolumn{4}{|l|}{ Women ( $\mathrm{n}=2176)$} \\
\hline \multicolumn{4}{|c|}{ Medically certified absence§ (spells per 10 years): } \\
\hline 0 & $1234(22)$ & 1.00 & 1.00 \\
\hline$>0$ to 5 & $452(7)$ & $0.78(0.33$ to 1.84$)$ & $0.72(0.31$ to 1.71$)$ \\
\hline$>5$ & $490(27)$ & 2.66 (1.49 to 4.75$)$ & $2.26(1.24$ to 4.11$)$ \\
\hline \multicolumn{4}{|l|}{ Self rated health status: } \\
\hline Very good or good & $1413(27)$ & 1.00 & 1.00 \\
\hline Average or worse & $763(29)$ & 1.87 (1.10 to 3.18$)$ & $1.45(0.82$ to 2.56$)$ \\
\hline \multicolumn{4}{|c|}{ Longstanding illness, disability, or infirmity: } \\
\hline No & $1454(29)$ & 1.00 & 1.00 \\
\hline Yes & $722(27)$ & 1.77 (1.04 to 2.99$)$ & $1.39(0.79$ to 2.44$)$ \\
\hline \multicolumn{4}{|c|}{ Physical illness indicatorf: } \\
\hline No & $1913(46)$ & 1.00 & 1.00 \\
\hline Yes & $263(10)$ & 1.53 (0.77 to 3.03$)$ & $1.13(0.55$ to 2.29$)$ \\
\hline
\end{tabular}

${ }^{*}$ Employees with missing values for any predictors excluded from analyses.

†Adjusted for age and grade.

†Additionally adjusted for predictors shown in table.

$\S \mathrm{P}$ for linear trend $<0.01$ in men and women.

१Diabetes, diagnosed heart disease, hypertension, abnormalities on electrocardiogram, respiratory illness.

Women had a higher rate of absence than men. In accordance, they had higher morbidity, poorer self rated health, more symptoms, and more psychiatric morbidity. Although differences in perceptions of health, behaviours in response to illness, and responsibilities at home may contribute to sex differences in absence rates, the predictive validity of sickness absence seems to be independent of sex. Medically certified absences predicted mortality in a similar way for men and women. The observed discrepancy between a higher absence rate and a lower death rate in women than in men is similar to those found for self rated measures of morbidity. ${ }^{23}{ }^{24}$ This suggests that medically certified absences could be used as a measure of health within sex groups.

In contrast to medically certified sick leaves, no significant linear association existed between self certified sickness absence and mortality. However, our findings suggest that, compared with no absence, taking a few absences decreases rather than increases the risk of mortality. This U shaped association was statistically significant in men. Short term absences may represent healthy coping behaviours or may be otherwise affected by factors causing variation in the threshold of taking sick leave.

\section{Conclusion and policy implications}

Medically certified sickness absences may well capture the full array of illnesses employees experience during their job contract. Our findings on mortality indicate that these routinely collected data could be used as a

\section{What is already known on this topic}

Sickness absence records are collected routinely in many workplaces; certified absences are also a byproduct of the medical care process

The usefulness of absence rate as an indicator of health has remained uncertain

\section{What this study adds}

All cause mortality gradually increased as the certified absence rate increased in both men and women

Rate of certified absence was a more powerful predictor of mortality than were established self reported health measures and available objective measures of specific medical conditions

Information on certified absence spells could be used as a global measure of health differentials between employees

global measure of health differentials between employees.

We thank all participating civil service departments and their welfare, personnel, and establishment officers; the Occupational Health and Safety Agency; the Council of Civil Service Unions; all participating civil servants in the Whitehall II study; all mem- 
bers of the Whitehall II study team; and Jaana Pentti from the Finnish Institute of Occupational Health.

Contributors: All authors designed the hypothesis, analysed the data, and wrote the paper. MGM is the director of the Whitehall II study. MK is the guarantor for this paper.

Funding: The Whitehall II study has been supported by grants from the Medical Research Council; British Heart Foundation; Health and Safety Executive; Department of Health; National Heart Lung and Blood Institute (HL36310), NIH, USA; National Institute on Aging (AG13196), NIH, USA; Agency for Health Care Policy Research (HS06516); and the John D and Catherine T MacArthur Foundation research networks on successful midlife development and socio-economic status and health. MK, who also works at the University of Helsinki, Finland, and JV were supported by the Academy of Finland (projects 44968 and 77560) and the Finnish Environment Fund; JEF is supported by the MRC (grant number 47413); MJS is supported by a grant from the British Heart Foundation; and MGM is supported by an MRC research professorship. Competing interests: None declared.

Ethical approval: University College London Medical School committee on the ethics of human research gave approval for the Whitehall II study.

1 Marmot M, Feeney A, Shipley M, North F, Syme SL. Sickness absence as a measure of health status and functioning: from the UK Whitehall II study. J Epidemiol Community Health 1995;49:124-30.

2 Folger R, Belew J. Nonreactive measurement: a focus for research on absenteeism and occupational stress. Res Organiz Behav 1985;7:129-70.

3 Prins R, de Graaf A. Comparison of sickness absence in Belgian, German, and Dutch firms. Br J Ind Med 1986;43:529-36.

4 Kristensen T. Sickness absence and work strain among Danish slaughterhouse workers: an analysis of absence from work regarded as coping behaviour. Soc Sci Med 1991;32:15-27.

5 Rael EGS, Stansfeld SA, Shipley M, Head J, Feeney A, Marmot M. Sickness absence in the Whitehall study, London: the role of social support and material problems. J Epidemiol Community Health 1995;49:47481.

6 Vahtera J, Kivimäki M, Pentti J. Effect of organisational downsizing on health of employees. Lancet 1997;350:1124-8.

7 Ferrie JE, Shipley MJ, Marmot MG, Martikainen P, Stansfeld S, Davey Smith G.Job insecurity in white-collar workers: towards an explanation of associations with health.J Occup Health Psychol 2001;6:26-42.

8 Vahtera J, Pentti J, Kivimäki M. Sickness absence as a predictor of mortality among male and female employees. J Epidemiol Community Health (in press).
9 Marmot MG, North F, Feeney A, Head J. Alcohol consumption and sickness absence: from the Whitehall II study. Addiction 1993;88:369-82.

10 North F, Syme SL, Feeney A, Head J, Shipley MJ, Marmot MG. Explaining socioeconomic differences in sickness absence: the Whitehall II study. BMJ 1993;306:361-6.

11 North FM, Syme L, Feeney A, Shipley M, Marmot M. Psychosocial work environment and sickness absence among British civil servants: the Whitehall II study. Am J Public Health 1996;86:332-40.

12 Stansfeld S, Head J, Ferrie J. Short-term disability, sickness absence, and social gradients in the Whitehall II study. Int J Law Psychiatry 1999;22:425-39.

13 Stansfeld SA, Rael EG, Head J, Shipley M, Marmot M. Social support and psychiatric sickness absence: a prospective study of British civil servants. Psychol Med 1997;27:35-48.

14 Marmot MG, Davey Smith G, Stansfeld S, Patel C, North F, Head J, et al. Health inequalities among British civil servants: the Whitehall II study. Lancet 1991;337:1387-93.

15 Rose G, Hamilton PS, Keen H, Reid DD, McCartney P, Jarrett RJ. Myocardial ischaemia, risk factors and death from coronary heart-disease. Lancet 1977;1:105-9.

16 Taylor PJ. Occupational and regional associations of death, disablement, and sickness absence among post office staff 1972-75. Br J Ind Med $1976 ; 33: 230-5$

17 Idler EL, Benyamini Y. Self-rated health and mortality: a review of twenty-seven community studies. J Health Soc Behav 1997;38:21-37.

18 Mansson N-O, Rastam L. Self-rated health as a predictor of disability pension and death-a prospective study of middle-aged men. Scand J Public Health 2001;29:151-8.

19 Stamler J, Stamler R, Neaton JD, Wentworth D, Daviglus ML, Garside D, et al. Low risk-factor profile and long-term cardiovascular and noncardiovascular mortality and life expectancy: findings for 5 large cohorts of young adult and middle-aged men and women. JAMA 1999;282:2012-8.

20 Miller TQ, Smith TW, Turner CW, Guijarro ML, Hallet AJ. A meta-analytic review of research on hostility and physical health. Psychol Bull 1996;119:322-48.

21 Kivimaki M, Leino-Arjas P, Luukkonen R, Riihimaki H, Vahtera J, Kirjonen J. Work stress and risk of cardiovascular mortality: prospective cohort study of industrial employees. BMJ 2002;325:357-61.

22 Kivimäki M, Vahtera J, Koskenvuo M, Uutela A, Pentti J. Response of hostile individuals to stressful change in their working lives: test of a psychosocial vulnerability model. Psychol Med 1998;28:903-13.

23 Heinrich J, Liese AD, Lowel H, Keil U. Self-rated health and its relation to all-cause and cardiovascular mortality in southern Germany: results from the MONICA Augsburg cohort study 1984-1995. Ann Epidemiol 2002;12:338-45.

24 Heistaro S, Jousilahti P, Lahelma E, Vartiainen E, Puska P. Self-rated health and mortality: a long term prospective study in eastern Finland. J Epidemiol Community Health 2001;55:227-32.

(Accepted 2 July 2003) 